\title{
A formação matemática para o ensino dos saberes elementares em tempos de Reforma da Escola Normal do Paraná (Anos de 1920)
}

\author{
Iara da Silva França* \\ Neuza Bertoni Pinto**
}

\section{Resumo}

O artigo aborda a formação matemática dos professores primários no Paraná e tem por objetivo compreender como os saberes elementares matemáticos foram contemplados na reforma levada a efeito por Lysimaco Ferreira da Costa, nos anos de 1920 e direcionada por Prieto Martinez para a modernização do ensino primário do estado. Amparado pelo referencial teórico-metodológico da história cultural, o presente estudo é norteado pela questão: na formação matemática dos professores do Paraná, o que mudou, por que e para que mudou, após a Reforma da Escola Normal? Com a reforma foram introduzidas disciplinas mais voltadas às práticas de ensino na escola primária e que favoreceram a renovação dos métodos de ensino e dos recursos didáticos, reorganização curricular que repercutiu na qualidade da formação matemática dos futuros professores do ensino primário do estado.

Palavras-chave: Formação de Professores. Ensino de Matemática. História da Educação.

\footnotetext{
* Doutora em Educação pela Pontifícia Universidade Católica do Paraná (PUC/PR). Professora da Secretaria Estadual do Paraná e do Instituto Superior do Litoral do Paraná (ISULPAR).

** Doutora em Educação pela Universidade de São Paulo (USP). Professora do Centro de Teologia e Ciências Humanas, Educação e da Pós-Graduação em Educação da Pontifícia Universidade Católica do Paraná (PUC/PR).
} 


\section{Introdução}

Os anos de 1920 foram essenciais para o desenvolvimento de ações que visavam mudanças qualitativas na formação dos professores para atender ao grande contingente de escolas primárias que se espalhavam por todo o Paraná e poder atender aos anseios políticos e sociais do projeto republicano.

Na história da educação matemática, estudos locais ${ }^{1}$ sobre saberes elementares ${ }^{2}$ matemáticos do ensino primário têm favorecido maior compreensão de momentos históricos que fizeram a diferença na formação matemática de normalistas, como o que este artigo se propõe destacar, relativo a uma reforma levada a efeito, nos anos de 1920, no Paraná, com repercussão em diversas mudanças do ensino primário e Normal do estado.

Com o objetivo de compreender essas mudanças decorrentes da Reforma da Escola Normal do Paraná $^{3}$, o estudo analisa o redimensionamento das disciplinas do referido curso e as intervenções que favoreceram a formação matemática dos professores. Amparado pelo referencial teórico metodológico da história cultural, em autores como Chervel (1990), Chartier (1990) destaca o antes e o depois da reformulação das disciplinas do referido curso de formação e a ênfase dada à melhoria do ensino primário do período de 1920.

Os documentos para o estudo constituem-se em Relatórios, Mensagens de Governo, Códigos e Programas de Ensino, que podem ser consultadas no Repositório da UFSC ${ }^{4}$.

\section{Novos tempos, Reformas e novos rumos para a Educação}

Num tempo em que a educação era vista como instrumento de "reconstrução social, política e moral" (TANURI, 1979, p. 153), foram desencadeadas as Reformas Estaduais 5 que marcaram os anos de 1920 e que, apesar de seguirem na maioria das vezes o modelo paulista ${ }^{6}$, foram sendo implantadas com características próprias nos estados brasileiros onde se estabeleceram.

A educação, tanto em nível nacional quanto estadual, passa por diferentes momentos no decorrer da década de 1920 em que destacamos a efervescência social do pós-guerra, a renovação educacional das reformas estaduais e o protagonismo do método intuitivo no ensino primário.

A Escola Normal foi disseminadora dos princípios propagados pelas Reformas dos anos de 1920, de uma educação que ensina levando em consideração os direitos da criança, de um ensino voltado aos interesses do aluno, com atenção pedagógica voltada para um ensino harmônico que levava 
em consideração o psicológico e o biológico do aluno, além de ensiná-lo o culto à Pátria e ao nacional (MARTINEZ, 1920, 1922, 1924).

Ao tempo do "entusiasmo pedagógico", a Escola Normal foi responsável pela formação dos professores para as escolas que se abriam e mais tarde com o "otimismo pedagógico" (NAGLE, 1977, p. 264), pela qualificação profissional desses professores. Fundamental para a reorganização de um país seria uma educação capaz de atender aos anseios sociais nos anos de 1920 e, nesse sentido, Escola Normal, instituição oficialmente formadora dos professores primários, foi expandida para novos espaços geográficos e renovada quanto aos métodos e técnicas de ensino, buscando atender as necessidades de formação não só quantitativa como qualitativa de professores primários do período em estudo.

A formação do professor tornou-se condição fundamental para o desenvolvimento da escola e as mudanças empreendidas na década de 1920 foram basilares para as transformações em relação ao ensino nas Escolas Normais paranaenses.

As reformas estaduais sugeriam mudanças na educação brasileira que atendessem às necessidades da nação em seu ideal de modernidade ${ }^{7}$. Tais mudanças estavam pautadas em novas teorias e métodos educacionais oriundos de pedagogos europeus e americanos, como Maria Montessori, Froebel e Dewey, dos quais seriam extraídas as ideias e os métodos necessários às mudanças na realidade educacional e social do país.

A instrução pública preocupava os governantes do país e o mesmo acontecia no estado do Paraná, pois a concepção do período era de que somente pela instrução popular o país conseguiria a estrutura necessária para o seu crescimento. Nesse contexto, a década de 1920 nesse estado foi marcada por importantes investimentos na educação, dentre eles as reformas levadas a efeito e voltadas à expansão e modernização da escola primária, assim como na melhoria da formação de seus professores.

Nesse empreendimento, dois personagens foram fundamentais: Cesar Prieto Martinez e Lysímaco Ferreira da Costa. O primeiro, pedagogo paulista que veio ao Paraná e empreendeu diversas ações em prol da educação primária do estado, dentre outras, ações voltadas à expansão das escolas primárias e à melhoria da qualidade do ensino nelas ministrado, de modo especial, as iniciativas voltadas para a melhor qualificação dos professores e a difusão de métodos modernos para o ensino dos saberes elementares matemáticos (COSTA, 1987). E o segundo, paranaense, destacou-se especialmente pela proposta elaborada para modernizar as Escolas Normais do estado: "Bases Educativas para a organização da nova Escola Normal Secundária”, em 1923. 
Entre as transformações da Educação paranaense nessa década, inclui-se a construção dos edifícios que abrigaram as três primeiras Escolas Normais do Paraná, a Escola Normal Secundária e as duas Escolas Normais Primárias, de Ponta Grossa e Paranaguá, localizadas em pontos nevrálgicos para a economia do estado.

\section{A formação de professores primários no Paraná dos anos de 1920}

As necessidades educacionais de cada período são decorrentes de vários fatores, entre os quais, as ideologias políticas e sociais contemporâneas e construídas no decorrer da história. Apesar do empenho dos governantes, em especial, Caetano Munhoz da Rocha (1920-1928), em relação à educação e de sua utilização como mola propulsora para o desenvolvimento, a década de 1920 assistia ainda um quadro de analfabetismo e de necessidade de expansão da Instrução Pública no Estado do Paraná.

Embora algumas medidas fossem tomadas nesse estado para a expansão da escolarização, em seu relatório de 1920, Martinez já se mostrava preocupado não somente com a questão do analfabetismo no Brasil, mas em propor soluções para tal situação, argumentando sobre as maiores possibilidades de produção de cidadãos alfabetizados e na consequente ampliação da arrecadação do Estado, que é “de todos os paranaenses e depende da eficácia de cada um” (MARTINEZ, 1920, p. 4).

Mesmo afirmando que os métodos de ensino eram alvo de discussões no tocante aos problemas relacionados à Instrução Pública do Paraná, Martinez considerava que o problema maior era o preparo do professor: "'Repito aqui o que disse nas instrucções recentes aos snrs. professores: 'Não é do número de escolas que depende unicamente a disseminação do alphabeto; mas sobretudo da efficiencia das escolas e, portanto, dos mestres"” (MARTINEZ, 1920, p. 6).

Para a alfabetização dos paranaenses não bastaria construir escolas, seria necessário professores eficientes e tal fato se daria por meio de uma formação específica para ensinar.

Nessa época, o Paraná já possuía uma Escola Normal na capital do estado que iniciou seu funcionamento em 1876, embora sem uma sede própria. Assim, no que se refere à formação de professores, entre os episódios que fizeram parte das ações governamentais ligadas a um Projeto de ensino, que tinha como objetivo a expansão do estado, destacamos o lançamento das "Bases Educativas para a organização da Nova Escola Normal Secundária” e a organização da I Conferência Nacional de Educação, além da já citada construção das três Escolas Normais paranaenses. 


\section{A reforma da Escola Normal do Paraná: consequências}

A Escola Normal do Paraná surgiu pela necessidade de qualificação e seleção dos professores para atender as escolas que estavam sendo criadas e cresciam devido ao aumento da população e das necessidades sociopolíticas da época. Segundo Straube (1993), essa Escola Normal foi criada anexa ao Instituto de Preparatórios ${ }^{8}$, pela Lei $\mathrm{n}^{\mathrm{o}}$ 456, de 12 de abril de 1876. Ambos os estabelecimentos de ensino ficaram sob a direção do Inspetor Geral, escolhido pelos professores do Instituto.

O curso da Escola Normal do Paraná iniciou dividido em dois anos, sendo as Cadeiras do primeiro ano: Gramática Nacional, Pedagogia e Metodologia Instrução Moral e Religiosa; e do segundo ano: Aritmética, Geometria, Geografia e História do Brasil e Direito Público. O Instituto Paranaense teria também anexo uma Escola Primária onde alunos da Escola Normal pudessem exercitar-se no ensino prático (STRAUBE, 1993).

A Escola Normal paranaense, cujas duas primeiras décadas do século XX foram de mudanças e conflitos, passou a denominar-se "Escola Normal Secundária" a partir da Lei no 2.114, de 25 de março de 1922 (STRAUBE, 1993) e sua sede foi separada do Ginásio Paranaense e inaugurada em 7 de setembro de 1922. A autonomia didática da Escola Normal por meio de uma reforma era necessária e urgente e essa conquista viria quando estivesse instalada em sua nova sede.

O projeto de reformulação da Escola Normal, proposto pelo então diretor Lysímaco Ferreira da Costa, atendia ao plano de desenvolvimento do estado idealizado por Caetano Munhoz da Rocha e foi regulamentado pelo Decreto $\mathrm{n}^{\mathrm{o}} 274$, de 26 de março de 1923 (STRAUBE, 1993), em face das

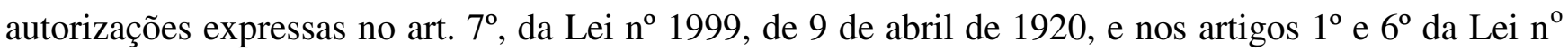
2.114, de 25 de março de 1922 (STRAUBE, 1993). Com o Decreto no 274, de 1923, passou a Escola Normal a denominar-se Escola Normal Secundária, devido à sua posição em relação às Escolas Normais Primárias, pois seu plano de estudos comportava também a formação de professores para lecionar nessas Escolas Normais.

Assim, ainda no ano de 1923, o diretor da Escola Normal Secundária, Lysímaco Ferreira da Costa (1923), após ter elaborado um novo regulamento para a Escola Normal lança as "Bases Educativas para a Organização da Nova Escola Secundária do Paraná”, que traziam as ideias e determinação de uma Reforma não apenas para a Escola Normal, mas também para o Ensino Primário. 
O documento "Bases Educativas para a Organização da Nova Escola Normal Secundária do Paraná" foi o primeiro a reorganizar o regimento do Curso Normal (PARANÁ, 1924). Segundo seu próprio idealizador, Lysímaco da Costa, a finalidade era “a preparação scientífica e profissional completa do professor" (COSTA, 1923, p. 67). Tinha como pressupostos a necessidade de preparar o normalista para conhecer o meio em que iria atuar, proporcionando-lhe a formação necessária para que transmitisse aos seus alunos os conhecimentos mínimos que lhes seriam úteis para serem bons cidadãos, afeitos ao trabalho, com bons hábitos morais e mentais e noção de deveres cívicos.

Era exigido do professor que tivesse um caráter reto e uma severa linha de conduta para sensibilizar seus alunos com seus exemplos (COSTA, 1923). Lysímaco se propunha a ensinar os professores a aplicarem nas aulas os novos métodos, processos e sistemas de ensino.

Funcionando em sua nova sede, a Escola Normal Secundária precisou também de reorganização e revisão do regimento do curso (PARANÁ, 1924) e o seu Programa passou por algumas mudanças, entre elas a supressão da Cadeira de Francez, que seria novamente recolocada no Programa das Escolas Normais do Paraná pela Lei n ${ }^{0} 2.619$, de 21 de março de 1928.

A preocupação do Diretor da Escola Normal era de que os futuros professores tivessem um ensino, na sua concepção, insuficiente e que não os prepararia para a "prática escolar", visto se aprofundarem muito naquilo que para Lysímaco da Costa (1923) não era o mais importante: os conhecimentos gerais.

Importante observar que entre esses conhecimentos considerados Gerais, encontravam-se a Aritmética e a Geometria. Lysímaco continua sua explanação sobre a necessidade de prática para os alunos normalistas, para quem não adiantaria apenas o conhecimento teórico, fazendo uma analogia com o ofício do médico, afirmava: "Persistir em tal regimen seria o mesmo que fazer médicos perfeitamente conhecedores dos remédios que curam, mas, que não sabem diagnosticar" (COSTA, 1923, p. 13).

Com propostas fundamentadas especialmente em Herbat, o Diretor da Escola Normal, ao lançar as Bases Educativas para a Nova Escola Normal Secundária, fez uma crítica ao Plano de Estudos até então utilizado pela Escola Normal devido à ênfase dada à formação geral do normalista, em detrimento de sua formação específica. Sobre esse assunto, nas palavras de Lysímaco da Costa (1923, p. 12, grifo nosso): “[...] não foi dada a devida importância á parte profissional propriamente dita, a única que justifica a razão de ser de uma Escola Normal”. 
Lysímaco da Costa (1923, p. 13) justifica sua crítica explicando que os normalistas podem ter um "sólido preparo" nas "cadeiras" das disciplinas de cunho geral, mas se o estudo da Pedagogia fosse "equiparado" às demais disciplinas, ficaria reduzida sua importância à mesma que qualquer outra matéria, o que reduziria a "preparação" dos normalistas para mais tarde encontrarem soluções para os problemas pedagógicos.

A necessidade de professores devido à demanda dos municípios paranaenses onde não havia Escola Normal precisava ser suprida e essa preocupação, já datando do início dos anos de 1920, conforme os Relatórios dos Inspetores do Ensino que levou à construção de outras duas Escolas Normais, inicialmente nas cidades de Ponta Grossa e Paranaguá.

Tais municípios foram escolhidos por sua importância no contexto econômico e social do estado e por se localizarem em pontos geográficos estratégicos do Paraná: a primeira na promissora região chamada de "Campos Gerais" e a segunda no litoral, porta de entrada e de saída de pessoas e produtos.

As Escolas Normais Primárias de Ponta Grossa e de Paranaguá foram criadas pela Lei no 2.064, de 31 de março de 1921, e regulamentado o seu funcionamento pelo Decreto $\mathrm{n}^{\mathbf{0}} 135$, datado de 12 de fevereiro de 1924. A primeira iniciou seu funcionamento em 1924 e a segunda, em 1927, ambas seguindo as Bases Educativas para a nova Escola Normal Secundária com pequenas adaptações, por serem Escolas Normais Primárias.

De acordo com o Decreto nº135, de 12 de fevereiro de 1924, o Curso Normal tinha a duração de três anos, com as matérias assim organizadas: no primeiro ano, pelas disciplinas gerais de Português, Aritmética, Geografia, Desenho, Música, Ginástica, Trabalhos Manuais e Pedagogia; no segundo ano, Português, Álgebra, Geografia, Desenho, Música, Ginástica, Trabalhos Manuais, Psicologia e Ciências Físicas Naturais; e no terceiro ano, Português, Álgebra, Geografia, Desenho, Música, Ginástica, Trabalhos Manuais, Ciências Físicas Naturais, Literatura, História do Brasil, Educação Moral e Cívica e Metodologia e Prática Pedagógica.

Uma característica comum às três Escolas Normais do Paraná era a ênfase dada à formação geral dos normalistas, visto que a carga horária semanal das disciplinas como Português, História, Matemática e outras era de quatro aulas semanais, enquanto que às disciplinas relacionadas ao "ofício do professor", como Metodologia e Prática Pedagógica, eram dedicadas três aulas semanais.

Inicialmente, uma das características que diferenciava a Escola Normal Secundária das Escolas normais Primárias, de Ponta Grossa e Paranaguá, era a organização do seu ensino em dois Cursos 
Normais: o Curso Geral (com duração de três anos) e o Curso Especial (que durava um ano e meio), enquanto nas Escolas Normais Primárias o curso tinha duração de três anos.

O Curso da Escola Normal Secundária, chamado "Geral”, consistia em um Curso onde as disciplinas consideradas gerais ${ }^{9}$ eram ensinadas até o terceiro ano, ficando para o quarto e quinto anos, o trabalho com as "matérias pedagógicas 10 ".

Em sua proposta da Reforma, Lysímaco pressupunha como finalidade desse Curso Geral da Escola Normal, "Ministrar aos normalistas os conhecimentos que devem transmitir mais tarde aos seus discípulos e preparar a cultura geral do futuro professor são os seus fins" (COSTA, 1923, p. 15).

Já o Curso Especial, além dos alunos que tivessem concluído o terceiro ano da Escola Normal Secundária era ministrado aos alunos que já tivessem feito o Curso Normal Primário em uma das Escolas Normais Primárias do estado com duração de três anos, ou mesmo aqueles que tivessem feito outro curso secundário (Ginásio) e quisessem complementar ${ }^{11}$ com a habilitação para o magistério.

O Diretor da Escola Normal justifica que o conhecimento de um normalista deve ser de uma cultura geral para que o curso possa ser considerado bom e para que o futuro professor, quando em sala de aula, possa se impor aos seus alunos por meio de sua ampla cultura.

Quanto às Escolas Normais Primárias, o Curso Normal, concluído em três anos, poderia ser complementado com mais um ano e meio de estudos na Escola Normal Secundária, o que daria a possibilidade ao concluinte de participar de Concurso para lecionar nas Escolas Primárias, enquanto o concluinte destas últimas seriam professores nas escolas primárias do estado.

Para a formação do normalista de acordo com a nova organização, Lysímaco da Costa anuncia como deverá ser o Curso Normal da Escola Normal Secundária e a distribuição dos programas relativos ao curso:

Attendendo ás necessidades do nosso meio e ás possibilidades finnanceiras do Estado, o Curso Geral realizará efficazmente o seu destino em três annos, com a seguinte distribuição das matérias:

$1^{\circ}$ ANNO

Português: três aulas por semana.

Geographia Geral e Chorographia do Brasil: três aulas por semana.

Arithmetica e Algebra: seis aulas por semana.

Desenho: duas aulas por semana.

Musica: duas aulas por semana.

Trabalhos de Agulha e Economia Domestica (para o sexo feminino): duas aulas por semana.

Trabalhos Manuaes: duas aulas por semana.

Gimnastica: duas aulas por semana. 
$2^{\circ}$ ANNO

Português: três aulas por semana.

Geometria Plana: três aulas por semana.

Physica e Chimica: quatro aulas por semana.

Historia G. da Civilização: três aulas por semana.

Desenho: duas aulas por semana.

Musica: duas aulas por semana.

Trabalhos de Agulha e Economia Domestica (para o sexo feminino): duas aulas por semana.

Trabalhos Manuaes: duas aulas por semana.

Gimnastica: duas aulas por semana.

$3^{\circ}$ ANNO

Português:quatro aulas por semana.

Historia do Brasil: três aulas por semana.

Historia Natural: três aulas por semana.

Geometria no Espaço: três aulas por semana.

Desenho: duas aulas por semana.

Musica: duas aulas por semana.

Trabalhos de Agulha e Economia Domestica (para o sexo feminino): duas aulas por semana.

Trabalhos Manuaes: duas aulas por semana.

Gimnastica: duas aulas por semana.

PRIMEIRA OBSERVAÇÃO. São matérias de exames finaes:

no $1^{\circ}$ anno - Arithmetica e Algebra e Geographia Geral e Chorographia do Brasil.

no $2^{\circ}$ anno - Physica e Chimica e Historia da Civilização;

no $3^{\circ}$ anno - Todas. (COSTA, 1923, p. 15-16).

Analisando o Programa do Curso Geral observamos que havia a valorização das matérias da área de Matemática, que eram ministradas por "Lentes Catedráticos"12 da mesma forma que Português, Geografia e História. No primeiro ano, a quantidade de aulas de Aritmética e Álgebra (seis aulas) equivaliam ao número de aulas das demais matérias cujos professores eram "lentes". As disciplinas como Desenho, Música, Ginástica e Trabalhos Manuais eram ministradas por professores não catedráticos e possuíam carga horária menor, sendo duas por semana.

Em seguida a essa distribuição do Ensino Geral no Curso Normal, o Diretor do Ginásio Paranaense e da Escola Normal explica como deverão ser os exames em algumas matérias específicas, entre elas Geometria Plana, do segundo ano, que "Constará de uma prova escripta sobre questões relativas a um dos pontos do programma" (COSTA, 1923, p. 16), e sobre o exame de Desenho que “[...] será uma prova graphica sobre assumpto escolhido na hora do exame” (COSTA 1923, p. 16). Quanto à Aritmética e algumas outras matérias, Lysímaco orienta que sejam feitas as médias anuais, visto serem de simples promoção. O detalhe é que Aritmética e Álgebra, da mesma forma que Geografia, eram as únicas matérias que teriam exames finais no primeiro ano. No que se refere às 
diferenças entre as provas de exame de Geometria e Desenho, a primeira por seu caráter de matéria teórica nesse tempo, para seu exame era proposto um dos "pontos do Programa", enquanto que Desenho, por sua característica mais prática, com construções feitas pelo aluno normalista, tinha para o exame uma prova gráfica.

Os professores de cada disciplina tinham seus horários organizados de forma que pudessem atender a todas as turmas do Curso Geral.

A organização do horário do professor da Cadeira das matemáticas, por exemplo, tem suas aulas escolhidas nos primeiros horários da manhã. O professor que lecionava uma disciplina ensinava sua respectiva Metodologia.

Quanto ao Curso Especial, para Lysimaco da Costa (1923, p. 19) suas finalidades eram:

Dar ao futuro educador uma boa technica methodologica, apoiada nos principios geraes e regras da Pedagogia, das noções fundamentaes da psychologia da Educação, para que possa efficazmente e o mais rapidamente possível, transmitir aos seus escolares os conhecimentos havidos no curso geral e determinados pelo programma de ensino, tal é o seu fim.

As orientações referentes ao Curso Especial foram cuidadosamente detalhadas pelo diretor Lysímaco, que sobre o mesmo dizia: "Ministrar ao normalista o ensino completo do processo psychico do conhecimento e do processo didactico do ensino, é fim capital deste curso, como essencial é que delle sahia o normalista senhor perfeito da technica da didactica" (COSTA, 1923, p. 20).

O dizer do Diretor da Nova Escola Normal Secundária deixa claro sua preocupação em "formar" um professor primário com conhecimentos que lhe possibilite ficar "[...] bem preparado para o exercício de suas funções" (COSTA, 1923, p. 9), com noções de Psicologia e conhecedor da Didática, cuja prática se desenvolveria durante todo o quarto ano do Curso Normal.

A organização dessas matérias do Curso Especial ficou assim estabelecida:

$4^{\circ}$ ANNO $-1^{\circ}$ Semestre. De 15 de janeiro a 31 de maio; 90 dias úteis, no mínimo. As aulas terão inicio com as da Escola de Applicação (Grupo Annexo).

Psychologia: seis aulas por semana.

Methodologia Geral: duas aulas por semana.

Methodologia da Leitura e Escripta: tres aulas por semana.

Methodologia do Desenho: duas aulas por semana.

Hygiene e Agronomia: quatro aulas por semana.

$4^{\circ}$ ANNO $-2^{\circ}$ semestre. De $1^{\circ}$ de julho a 14 de novembro; 90 dias úteis, no mínimo. As aulas abrem-se com as da Escola de Applicação, depois das férias de inverno.

Moral e Educação Civica: Sua Methodologia. Noções de Direito Patrio e de Legislação Escolar - três aulas por semana.

PERSPECTIVA, Florianópolis, v. 34, n. 1, p. 142-171, jan./abr. 2016

http://www.perspectiva.ufsc.br 
Methodologia do idioma vernáculo: três aulas por semana.

Methodologia da Arithmetica: três aulas por semana.

Methodologia do Ensino Intuitivo: três aulas por semana.

Methodologia das Sciencias Naturaes: duas aulas por semana.

Methodologia da Geographia: tres aulas por semana.

$5^{\circ}$ ANNO $-1^{\circ}$ semestre. (Terceiro semestre do Curso Especial). De 15 de janeiro a 31

de maio. (numero de dias uteis e abertura como no primeiro semestre)

Puericultura: uma aula por semana.

Methodologia da Historia: três aulas por semana.

Methodologia da Geometria: duas aulas por semana.

Methodologia da Musica: duas aulas por semana.

Methodologia dos exercícios physicos: duas aulas por semana.

O Ensino dos Trabalhos Manuaes: duas aulas por semana.

Pratica e Critica Pedagogicas: quatro aulas por semana. (COSTA, 1923, p. 21, grifo nosso).

Ao que indica, a organização programática nas disciplinas assinaladas concentravam-se saberes elementares matemáticos que eram "praticados" sob a supervisão do professor da respectiva disciplina, como o que ocorria em São Paulo, em relação à presença de saberes elementares matemáticos nas atividades desenvolvidas na matéria Geometria e em Trabalhos Manuais, como foi observado por Camara e Pinto (2014, p. 5) ao localizarem documentos apresentando os conteúdos de 1921 e 1925 e, "Na matéria de Trabalhos Manuais, os alunos deveriam trabalhar de forma ativa, onde tinham que manusear formas geométricas e construir objetos diferenciados".

Ainda de acordo com as instruções contidas nas "Bases Educativas para a organização da Nova Escola Normal Secundária do Paraná”, o ensino dessa Escola Normal contaria com um corpo docente privilegiado, composto por “[...] cinco cathedráticos e cinco professores, no mínimo” (COSTA, 1923, p. 21).

Os professores chamados "lentes" eram aqueles que por sua formação prestavam concurso para o ingresso na Escola Normal e, embora não fosse uma das “disciplinas pedagógicas" que compunham o Curso Especial, $4^{\circ}$ ano do Curso Geral, observamos a importância da Matemática no Curso Normal pelo imperativo de um professor "lente" ocupar a "Cadeira de Matemática", além do número de aulas semanais dedicados a essa matéria. 


\section{A formação matemática dos professores primários do Paraná}

Os estudos sobre a formação matemática dos professores primários paranaenses nos permite ampliar a visão no que se refere às (re)criações e/ou transformações daquilo que foi proposto e que constituem os elementos de determinada cultura escolar, nos conduzindo à reconstituição da história da formação do professor primário do Paraná.

Nessa reconstituição, podemos distinguir duas etapas que marcaram a trajetória dessa formação no Paraná: a primeira, anterior à criação das Escolas Normais; e a segunda, iniciada com a estruturação e ampliação dessas escolas feitas a partir de reformas educacionais e com a construção de prédios próprios, estendendo-se até a década de 1930.

Os Cursos para Formação de Professores foram alvo de diversas reformas ${ }^{13}$, que em espaços e tempos diferente foram operando mudanças: no currículo, nos métodos, nas formas de ser e de pensar o ensino e, consequentemente, nos modos de fazer das escolas e dos seus integrantes, em especial, os professores.

No Paraná, a formação para ensinar Matemática nas Escolas Normais dos anos de 1920 poderia ser de dois tipos: a primeira, para a instrução geral do normalista, na Matemática ensinada no chamado Curso Geral; e a segunda, nas Metodologias da Aritmética e da Geometria, onde os conteúdos para ensinar Matemática estão atrelados àquilo que era ensinado dessa matéria no ensino primário.

Assim, a organização das disciplinas e dos programas de Matemática para a Escola Normal possuía mão dupla: havia as disciplinas que instruíam os normalistas numa Matemática para sua formação geral, idêntica à do Ginásio Paranaense, e que não parece pautada nas necessidades do professor primário para ensinar os conceitos matemáticos aos seus alunos. E especificamente para o ofício que os normalistas estão sendo preparados, há a Aritmética e a Geometria para ensinar nas Escolas primárias, trabalhadas nas aulas de Metodologia e Prática de Ensino, onde as lições dessas matérias na Escola Normal são propostas de acordo com os programas da escola primária.

Buscamos Chervel (1990) para nos elucidar sobre essa duplicidade de conceitos separando aquilo que é considerado "disciplinar" do avaliado como pedagógico. Esse autor esclarece que não há "existência autônoma" de uma disciplina, sendo constituída da combinação de "saberes e de métodos pedagógicos" (CHERVEL, 1990, p. 181), concepção essa que não parecia presente na formação matemática ofertada pela Escola Normal do Paraná no início dos anos de 1920. 
Em função dessa dupla situação, houve orientações do Diretor da Escola Normal Lysímaco da Costa a esse respeito, sobre todas as disciplinas e na postura do professor lente responsável, com a prática na Escola de Aplicação, inclusa aí, a Matemática.

A obrigação do professor de uma cadeira do curso geral é ensinar a methodologia respectiva no curso especial, levando ao mesmo tempo os alumnos á pratica diaria das lições dessa doutrina e fazendo cumprir os programmas do ensino primário, na Escola de Applicação, resolve um duplo problema que constitui duas grandes aspirações a realizar no ensino normal - a de pôr o lente da Escola Normal em contato com o ensino primário, do qual se acha divorciado, e a de obrigar o futuro normalista a praticar em todas as lições que mais tarde deverá ministrar á frente da sua escola. (PARANÁ, 1924, p. 68).

Apoiamo-nos na historiografia existente para afirmarmos que há fortes indícios dessa desconexão entre os profissionais de um nível de ensino e os processos de ensino do nível imediatamente anterior. De acordo com as palavras de Alcides Munhoz (PARANÁ, 1924), esse era o caso dos professores das Escolas Normais em relação às Escolas Primárias. Estudando a disciplina Complementos de Matemática na formação de pedagogos em meados do século XX, no Paraná, Pinto (2013, p. 11, grifo do autor) considerou ser possível "[...] identificar a filiação da disciplina à cultura profissional dos formadores, um rastro deixado nas representações profissionais dos formados por aqueles que para além da sala de aula conquistaram status profissional no meio acadêmico".

No início do século XX, possuindo apenas uma Escola Normal na capital do Paraná, havia dificuldade para a formação dos professores nos municípios e lugares mais afastados. A formação matemática desses professores, tanto quanto sua formação geral, nem sempre preenchia os requisitos necessários a um professor para ensinar nas escolas primárias do estado, pois muitos eram leigos, outros ainda apenas com o Curso Primário e muito poucos com estudos feitos na Escola Normal da capital.

Embora houvesse ações no sentido de orientar os professores para a sua prática, como a publicação da Inspetoria Geral do Ensino, que orientava os professores, estes precisavam mais do que algumas orientações esporádicas sobre exames ou sobre como ensinar os conteúdos que seriam "cobrados" nesses exames, em especial, a Matemática. A simples técnica das quatro operações fundamentais e a memorização da tabuada que precisava estar "na ponta da língua" não eram suficientes para que eles próprios e as crianças entendessem os conceitos implícitos nessas operações. 
Os professores normalistas possuíam a formação que possibilitava aplicar métodos de ensino, entretanto, nem todos eram formados pela Escola Normal.

Aos professores de matemática das Escolas Normais as respostas sobre o que ensinar eram ofertadas pelos programas que passavam pelo crivo da Inspetoria Geral da Instrução Pública. Esses Programas eram normalmente organizados pelos professores de cada disciplina e aprovados (ou não) pela Congregação da Escola Normal, reunida geralmente no início dos períodos letivos.

O como ensinar era atrelado ao o quê ensinar e se efetivava junto às escolhas feitas em relação aos métodos e na utilização dos recursos disponíveis. A formação matemática dos professores que ensinavam os normalistas parecia influenciar no como ensinar, visto que a maioria dos professores de matemática das Escolas Normais do Paraná, assim como os do Ginásio Paranaense, possuía formação em outras profissões ${ }^{14}$, como engenheiros e médicos.

Quando se trata de responder para que ensinar Matemática aumenta ainda mais a dificuldade, visto que essa resposta exige uma formação mais específica, com o conhecimento dos conceitos matemáticos que permeiam todo o processo de ensino e aprendizagem dessa matéria. Além disso, havia dois tipos de formação matemática, a formação geral, onde se incluíam as disciplinas: Aritmética, Álgebra e Geometria e a formação específica, com as Metodologias de cada uma delas. A questão é que a formação geral do normalista parecia apartada da formação específica, sendo a primeira para os conhecimentos gerais e esta última para tratar das "formas" que utilizaria para ensinar as matemáticas.

Antes da inauguração da sede própria da Escola Normal do Paraná, a denominação utilizada para a "rubrica" pelo Código de Ensino de 1917 era "matéria" (CHERVEL, 1990) e eram as seguintes que constavam em seus programas:

Art. 192 - O curso da Escola Normal, destinado á formação de professores para as escolas infantis, primarias e intermediarias do Estado, e dividido em quatro annos é constituido da forma seguinte:

$1^{\circ}$ anno: Portuguez, Francez, Arithmetica, Geographia Physica e Elementos de Cosmographia, Desenho linear, Musica, Trabalhos Manuaes;

$2^{\circ}$ anno: Portuguez, Francez, Arithmetica, Geographia Physica e Politica, Pedagogia (parte geral), Geometria Plana, Desenho, Musica, Trabalhos Manuaes;

$3^{\circ}$ anno: Portuguez, Chorographia do Brazil, Geometria no Espaço, Physica, Chimica, Pedagogia (parte especial), Historia Geral da Civilização, Desenho, Musica, Trabalhos Manuaes;

$4^{\circ}$ anno: Noções de Moral, Direito Patrio e Economia Politica; Historia Natural; Noções de Hygiene e Agronomia; Historia da Civilização no Brazil, especialmente no Estado do Paraná; Pratica Pedagógica.

$\S$ único - Haverá para todos os alumnos, exercicios de Gymnastica (PARANÁ, 1917, p. 54-55). 
O artigo 193 do mesmo Código de Ensino explicita as regras segundo as quais os lentes e professores de cada matéria deveriam organizar seus programas (PARANÁ, 1917). O Decreto Federal $\mathrm{n}^{\mathrm{o}} 11.530$ de 18 de março de 1915, conhecido como Lei Maximiliano, havia reorganizado o ensino secundário e superior na República, dando autonomia didática e administrativa aos estabelecimentos de ensino secundário.

O Código de Ensino de 1917 (PARANÁ, 1917) era, em muitos aspectos, idêntico ao Decreto nº 710, de 18 de outubro de 1915, também conhecido como Código de Ensino de 1915 (PARANÁ, 1915), onde a terceira e quarta regras do Artigo 193, em ambos os Códigos, dizem respeito ao ensino de Aritmética e Geometria e determinavam que:

$3^{\mathrm{a}} \mathrm{O}$ ensino de Arithmetica será o mais completo possivel, seguido constantemente de exercicios praticos e accrescido de noções de Algebra até equações do $1^{\circ}$ gráo.

$4^{\text {a }}$ No ensino de Geometria attender-se-á a natureza especial do curso da Escola Normal, limitada a materia ás theorias essenciaes, completadas pelas noções de Trigonometria Rectilinea, tudo com exercicios praticos constantes. (PARANÁ, 1917, p. 57).

A necessidade de modernização do ensino, tornando-o mais prático e utilitário, foi uma das consequências educacionais geradas por avanços do pensamento experimental e analítico, que, de acordo com Monarcha (2009), marcaram o final do primeiro século da Revolução Industrial. Valdemarin (1998, p. 68) explica que nesse tempo o ensino das matemáticas deveria ser orientado para o método intuitivo, devendo arremeter para o "[...] concreto, racional e ativo, denominado ensino pelo aspecto, lições de coisas ou ensino intuitivo" em oposição ao ensino "de caráter abstrato e pouco utilitário da instrução".

Nesse contexto, um Programa de Aritmética “o mais completo possível” (PARANÁ, 1917, p. 57) significava um ensino teórico seguido de exercícios e resolução de problemas aplicados ao cotidiano. No Programa de Aritmética constariam os saberes elementares de Aritmética e no de Álgebra apenas as primeiras noções desses saberes. Quanto à Geometria, seu ensino seria mais teórico, embora sempre seguido por exercícios, devido à "natureza especial" do Curso Normal, que não precisava aprofundar-se nos conteúdos, visto que o seu objetivo era preparar os normalistas para ensinar nas escolas primárias do estado e não para concorrer a uma vaga nos Cursos Superiores.

Roger Chartier (1994, p. 104) refere-se à legislação como um conjunto de "representações coletivas que incorporam nos indivíduos as divisões do mundo social e estruturam os esquemas de 
percepção e apreciação a partir dos quais estes classificam, julgam e agem”. Portanto, a legislação utilizada é aqui entendida como representação das aspirações políticas e sociais do tempo delimitado para este estudo.

\section{As matérias da área de Matemática nas Escolas Normais Paranaenses}

$\mathrm{Na}$ organização programática das disciplinas da área de Matemática dos Cursos Normais paranaenses da década de 1920 encontramos quatro matérias: Aritmética, Álgebra, Geometria e Metodologia que, apesar de um título genérico, tratava da Metodologia de Aritmética e de Geometria.

A organização de uma disciplina escolar inserida na formação de professores, passa pela seleção dos conteúdos, da metodologia e dos recursos utilizados por seus professores e que são aspectos importantes a serem considerados. Entender como tal organização foi sendo feita no decorrer da história da matemática escolar é um dos aspectos para o qual a história cultural muito tem contribuído, pois possibilita a análise de práticas escolares que foram se constituindo ao longo da história, em especial das disciplinas escolares, permitindo, assim, reconhecer os avanços e retrocessos enfrentados por determinada disciplina, na constituição dos seus saberes.

Cesar Prieto Martinez, que havia tido como uma de suas primeiras ações a separação da Escola Normal e do Ginásio Paranaense, já havia feito observações sobre a necessidade de reformulação dos programas para a formação de professores em seu relatório de 1920, afirmando que "Os actuaes programmas exigem modificação, de accordo com as necessidades da Escola, principalmente os das cadeiras de Pedagogia” (MARTINEZ, 1920, p. 15).

De acordo com o Inspetor Geral da Instrução Pública paranaense, os normalistas precisavam ser preparados para a sua função de ensinar, tendo matérias que lhe possibilitasse conhecer a natureza infantil para que pudessem encaminhar o seu trabalho, visando a formação física, intelectual e moral dos alunos. Para isso, explica suas ações: "Foram extendidas ao $3^{\circ}$ e $4^{\circ}$ anno varias materias, tendo-se em vista melhorar, tanto quanto possível, o preparo dos futuros professores" (MARTINEZ, 1920, p. 16).

Para essa reformulação inicial do Ensino Normal, foram acrescentadas: Antropologia e Pedagogia, no $2^{\circ}$ ano; Psicologia Infantil Aplicada à Educação, no $3^{\circ}$ ano; Metodologia Geral e História da Pedagogia, no $4^{\circ}$ ano. 
Assim, Martinez (1920, p. 16) justifica as mudanças feitas no Curso Normal em relação ao Programa de Pedagogia:

O programma de pedagogia passou, a titulo de experiencia, por uma completa reforma e comprehende:

a) Anthropologia, Pedagogia, no $2^{\circ}$ anno;

b) Psychologia infantil applicada á educação, no $3^{\circ}$ anno;

c) Methodologia Geral e Historia da pedagogia, no $4^{\circ}$ anno.

No segundo anno são ministrados todos os conhecimentos capazes de fazer conhecer ao professor, a natureza infantil e os conhecidos caracteristicos somáticos segundo os quaes o educando é reconhecido e classificado para receber do preceptor os cuidados pela sua natureza. No terceiro anno a Psychologia completa o estudo e fornece ao educador todos os dados de que necessita para encaminhar o seu trabalho, visando a formação physica,

intellectual e moral dos alumnos, o verdadeiro programma da Educação. No $4^{\circ}$ anno, a methodologia geral estuda a natureza dos methodos em si e a methodologia applicada mostra como se deve ensinar cada materia, em todas as classes, desde os casos geraes até os particulares. (MARTINEZ, 1920, p. 16).

Os saberes pedagógicos constantes no ensino de Pedagogia determinado pelo Código de Ensino de 1917 pareciam mais restritos, visto que, de acordo com o $8^{\circ}$ item do Art. 193, compreendia "noções essenciaes de Psycologia e de Logica applicadas", sendo "mais pratico do que theorico", para "incutir nos habitos dos futuros professores a arte de ensinar com o menor esforço e com o maior resultado" (PARANÁ, 1917, p. 57), mas não havia indicações do desenvolvimento do ensino das Metodologias.

A Matemática ensinada no Curso Normal à primeira vista restringia-se à Aritmética que era ensinada no $1^{\circ}$ ano, Álgebra no $2^{\circ}$ ano e Geometria no $3^{\circ}$ ano, entretanto, após a reformulação empreendida por Martinez (1920), as lições de Metodologia de Aritmética, Geometria e Desenho passaram a fazer parte dos saberes ensinados aos normalistas. Do mesmo modo, a matéria Desenho apresentava saberes matemáticos inseridos no seu programa, como atividades relacionadas à solução de “questões ou problemas de utilidade pratica; em aplicações ornamentais e industriais do desenho linear; ensaios topográficos, com aplicação da escala métrica em ensaios cartográficos, com aplicação das medidas e convenções geográficas e outros” (PARANÁ, 1917, p. 57).

Ainda como Diretor da Escola Normal, Lysímaco da Costa (PARANÁ, 1924), expunha ainda em seu Relatório os benefícios recebidos pela Escola Normal em ter nomeado como Lente da Cadeira de Pedagogia o próprio Inspetor Geral do Ensino, pelo Decreto n 542, de 26 de abril de 1920 (Paraná, 1924), e especifica as aulas dadas por Martinez dentro do programa executado. 
Após as aulas de Antropologia no $2^{\circ}$ ano e de Psicologia no $3^{\circ}$ ano, a Metodologia aparece em 1922 no $4^{\circ}$ ano, e nas 28 aulas dadas por Martinez, encontramos a "Metodologia de Arithmetica" da 12a à $15^{\mathrm{a}}$ "Licções", após terem sido dadas as "Licções de Methodologia" e "Methodologia de Linguagem" (PARANÁ, 1924, p. 7).

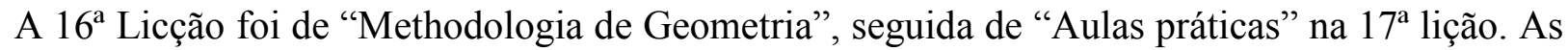
licções seguintes foram as das "Methodologias" das matérias de "Geographia, Sciencias Naturaes e a Sabbatina" (PARANÁ, 1924, p. 7).

Já na turma do ano de 1923, as aulas apresentaram pequenas mudanças, ao menos em seus registros, na nomenclatura utilizada e no número de aulas, que aumentou para 45 lições. A $20^{a}$ Licção refere-se ao "Aprendizado da Aritmethica", seguido da $21^{\mathrm{a}}$ com "Recapitulação" e da $22^{\mathrm{a}}$ até a $25^{\mathrm{a}}$ Licção com "Methodologia das Mathematicas"15" (PARANÁ, 1924, p.7).

Entre as outras Metodologias presentes nas aulas da Cadeira de Pedagogia, além da Metodologia de Geografia e de Ciências Naturais, outras lições são acrescentadas às aulas de Martinez, como "Methodologia de Português", "Aprendizado de Leitura", "Methodologia de História", "Prática Pedagógica", "Methodologia de Música", "Methodologia de Lição de Cousas" e "Methodologia de Desenho", dividida essa Metodologia em "Methodologia de Desenho: Theorias antigas e modernas; desenho à mão livre", "Methodologia de Desenho: Methodo Intuitivo; Desenho nos Estados Unidos" e “Aulas praticas sobre Desenho". Além disso, havia a 43ª Licção: "Disciplina Escolar" (PARANÁ, 1924, p. 7).

De acordo com a explanação de Lysímaco da Costa (1923), as matérias da área de Matemática, juntamente com as matérias "Linguagem" e "Leitura", aparecem com certo destaque nas "lições" dadas por Martinez, visto serem em número maior do que das demais matérias. Cada uma dessas matérias é trabalhada em seis lições, em 1922, e o mesmo número em 1923 (PARANÁ, 1924, p. 8).

Com a inauguração da nova sede da Escola Normal Secundária, em 1922, e da Reforma do Ensino paranaense a partir de 1923, as orientações em relação aos programas e à metodologia utilizada por lentes ou professores em suas disciplinas são especificadas pelo Diretor da Escola Normal Secundária em suas "Bases Educativas para a Organização da Nova Escola Normal Secundária do Paraná" (COSTA, 1923). No que se refere à Matemática, esse diretor afirma que "O lente de Mathematica ensinará mathematica para instrucção e uso dos alumnos no curso geral” (COSTA, 1923, p. 22). Nesse Curso Geral da Escola Normal Secundária, a proposta para o ensino das "matemáticas" era separada por disciplinas. Cabia ao professor ministrar o Ensino de Álgebra simultaneamente com o 
de Aritmética, sendo o último "reduzido às noções indispensáveis" (COSTA, 1923, p. 22). Lysímaco da Costa (1923, p. 22) propõe os seguintes encaminhamentos para os saberes aritméticos, algébricos e geométricos:

[...] dadas as quatro primeiras operações aritméticas, serão em seguida generalizadas em caracter algebrico; terminadas as seis operações arithmeticas e antes de ser abordado o estudo das proporções serão estudadas as equações do primeiro grao, seguindo então o restante das doutrinas arithmeticas conforme o programma a confeccionar; na Geometria Plana serão dadas tão somente as propriedades das figuras, consideradas em um plano que conduza efficazmente até a medida da extensão a duas dimensões e semelhantemente será na Geometria do Espaço para se atingir a medida da extensão a três dimensões.

No que tange aos saberes matemáticos, que seriam utilizados pelos normalistas de forma mais aplicada em sua função de professores primários, eram ensinados aos normalistas no Curso Especial, segundo as regras estabelecidas pelo Diretor da Escola Normal:

No Curso Especial, ensinará no $2^{\circ}$ semestre do $4^{\circ}$ anno, a Methodologia da Arithmetica, primeiro a parte geral, isto é: histórico, importância, requisitos do ensino, métodos e processos, modelos de lições, etc. e, em seguida, acompanhará, na Escola de Applicação, orientando e corrigindo a execução dos programmas dos Grupos Escolares, feitos pelos alumnos, de forma que todos se exercitem completamente até a finalização do semestre. No terceiro semestre $\left(1^{\circ}\right.$ do $5^{\circ}$ anno), ensinará a Methodologia da Geometria, isto é: histórico, importância da Geometria, methodos e processos, vicios, modelos de lição, etc. fazendo depois applicar os alumnos, na Escola de Applicação, a methodologia ensinada, as lições constantes dos programmas, até a finalização do semestre. (COSTA,1923, p. 22-23, grifos nosso).

No Curso Especial, que era voltado para a formação pedagógica dos normalistas, eram ministradas as Metodologias da Aritmética e da Geometria. Lysímaco da Costa (1923) deixa explícito o que deveria ser ensinado nessas Matérias: em ambas as Metodologias, durante um semestre deveria ser trabalhado pelo professor, além do histórico ${ }^{16}$ e da importância da Aritmética, os métodos, processos e os modelos das lições que seriam aplicadas na Escola de Aplicação ${ }^{17}$.

Algumas disciplinas mudavam sua denominação, sua inclusão e/ou exclusão em determinada série a cada ano. As disciplinas da área de Matemática não fugiam à regra, havendo, por exemplo, situações em que num mesmo Curso, num dado ano, a Aritmética é contemplada no $1^{\circ}$ ano e a Álgebra no $2^{\circ}$ ano para, no ano seguinte, fazerem ambas parte da organização do $1^{\circ}$ ano.

Para ensinar Matemática no Curso Primário, as normalistas necessitavam de um conhecimento geral sobre a matéria como base. Porém, os saberes matemáticos ensinados aos normalistas para seus 
conhecimentos gerais eram diferentes daqueles que seriam ensinados em sua prática docente, por isso, as aulas de Metodologia e de Prática de Ensino serviam de suporte para a sua prática para o exercício do magistério nas escolas primárias paranaenses.

Nesse tempo, ainda, ao professor primário cabia, prioritariamente, ensinar a ler, escrever e contar. Sendo assim, como esse professor primário, normalista e o não normalista ensinava as matérias do contar nas escolas primárias paranaenses?

\section{Dos Programas do Ensino Primário para os Programas da Escola Normal}

Na publicação do documento da Inspetoria Geral do Ensino do ano de 1921 sobre o Programa dos Grupos Escolares do Estado do Paraná, sob a Portaria n ${ }^{\circ} 86$ e de acordo com a Lei n ${ }^{0} 1.999$, de 9 de abril de 1920 (STRAUBE, 1993), assinado pelo Secretário Geral do Estado, Marins Alves de Camargo, encontramos bem detalhados os conteúdos a serem trabalhados com as crianças em cada série do Ensino Primário. No Programa para o $1^{\circ}$ ano constam as seguintes matérias: Leitura, Linguagem Oral, Linguagem Escrita, Caligrafia, Aritmética, Geometria, Geografia, História da Pátria, Instrução Moral e Cívica, Ciências Físicas e Naturais - Higiene, Música, Desenho, Trabalho Manual (acrescentando agulhas para a seção feminina) e Exercícios Ginásticos. O programa de Aritmética e Geometria apresenta-se da forma que segue:

$1^{\circ}$ Anno

ARITHMETICA

A) Rudimentos das primeiras operações com materiais concretos, servindo-se o alumno de tornos, pontos, taboinhas, etc.

B) Conhecimento directo dos grupos 3,4,5, etc. por um simples golpe de vista e sem contar.

C) Somma directa de objectos de 1 em 1, de 2 em 2, de 3 em 3, etc. até 20 e contagem de 10 em 10 até 100 .

D) Exercicios sobre as 4 operações até 100.

E) Leitura e escripta de números e usos dos signaes $+-x \div=$ praticados nas quatro operações.

F) Exercícios oraes e escriptos sobre os cálculos da carta de Parker, inclusive exercícios sobre fracções.

G) Estudo das quatro operações até 100, do modo mais concreto possível. Problemas ao alcance do raciocínio infantil.

H) Conhecimentos dos algarismos romanos. O relógio.

I) Conhecimento prático do metro, litro e kilo.

J) Leitura das cartas de Parker (PARANÁ, 1921b, p. 6).

GEOMETRIA 
Estudo dos solos geométricos: esphera, hemispherio, cubo, parallelepipedo, pyramide, prysmas e cylindro, quanto á forma, superfície, linhas, ângulos, etc.

Estudo comparativos entre esses sólidos. (PARANÁ, 1921b, p. 7).

O $2^{\circ}$ ano é composto pelas mesmas matérias, com exceção da nomenclatura dada aos Exercícios Ginásticos que agora aparece como simplesmente, Ginástica.

As matérias matemáticas continuam sendo Aritmética e Geometria, cujos programas estão assim dispostos:

\section{ARITHMETICA}

A) Estudo pratico da numeração oral e escripta até milhar. Estudo pratico da formação das unidades, dezenas, centenas e milhares.

B) Calculo mental de accordo com as lições das cartas de Parker, incluindo as fracções.

C) Continuação dos algarismos romanos.

D) Taboada de multiplicar até 10, por meio de tornos.

E) Leitura das cartas de Parker.

F) Estudo elementar completo das 4 operações fundamentaes até milhares. Exercicios práticos.

G) Conhecimento das unidades principaes de comprimento, superfície, capacidade e peso. Exercicios práticos correspondentes.

H) Conhecimento da moeda brasileira (PARANÁ, 1921b, p. 10).

GEOMETRIA

A) Ampliação do programma do $1^{\circ}$ anno.

B) Estudo das linhas, ângulos e superfície. (PARANÁ, 1921b, p. 10).

A matéria Desenho ainda não possuía as características que lhes foram sendo incorporadas mais tarde, de uma "matéria matemática", pois ainda não estava relacionada à Geometria e medidas ou conceitos matemáticos. Seu programa era inicialmente constituído da forma como podemos observar a seguir:

\section{DESENHO}

A) Desenho de animaes, plantas e objectos de uso commum, feitos a lapis, á vista do modelo do natural

B) Desenhos copiados ou inventados pelo alumno. (PARANÁ, 1921b, p. 12).

As matérias do $3^{\circ}$ ano permanecem as mesmas anteriores com o acréscimo de Economia Doméstica, que entre outros conteúdos, apresentava no item B, "Gastos e economias das famílias", onde possivelmente era desenvolvido algum tipo de trabalho com as operações fundamentais para o cálculo desses “gastos” (PARANÁ, 1921b, p. 16).

No programa do $3^{\circ}$ ano permanecem a Aritmética e a Geometria as matérias onde encontramos a Matemática ensinada no Primário, como se apresentam a seguir: 
ARITHMETICA

A) Estudo completo da numeração decimal

B) Estudo completo das quatro operações sobre inteiros. Problemas e questões práticas.

C) Leitura e escripta de números decimaes.

D) Reducção de fracções decimaes á mesma denominação.

E) Alteração das decimaes. Emprego da virgula.

F) Estudo completo das quatro operações decimaes, explicando-se a razão de ser de todas as operações.

G) Conhecimento pratico de fracções ordinarias.

H) Systema métrico. Conhecimento pratico das unidades de comprimento, superfície, volume e peso. Multiplos e submúltiplos das unidades métricas. Applicações práticas.

\section{GEOMETRIA}

A) Linhas: suas espécies; posição absoluta e relativa.

B) Traçado das linhas com o uso do compasso.

C) Divisão de uma recta em partes eguaes.

D) Angulos, triangulos, Rectangulos, quadriláteros e suas superfícies.

E) Medidas das areas.

F) Problemas e questões praticas. (PARANÁ, 1921b, p. 15).

O $4^{\circ}$ ano era o final do Curso Primário e novamente as matérias se repetiam com a matéria Trabalhos Manuaes sempre acrescentando um ou mais conteúdos para a seção feminina. A matéria Economia Domestica que apareceu no $3^{\circ}$ ano é suprimida no $4^{\circ}$ ano.

Os programas para Aritmética e Geometria aparecem como segue:

\section{ARITHMETICA}

A) Revisão do estudo feito no $3^{\circ}$ anno.

B)Fracções ordinárias. Fracções próprias, homegeneas e heterogêneas.

C) Reducção de numero mixto a fracção ordinária.

D) Conhecimento dos caracteres de divisibilidade.

E) Estudo pratico elementar do maximo divisor commum.

F) Reducção de fracções ordinárias ao mesmo denominador commum e simplificação.

G) Estudo pratico das quatro operações sobre fracções ordinárias.

H) Reducção das fracções ordinárias a fracções decimaes e vice versa.

I) Juros simples.

J) Systema métrico. Problemas e exercicios práticos.

\section{GEOMETRIA}

A) Revisão do estudo feito no $3^{\circ}$ anno.

B) Avaliação das areas dos triangulos e dos paralelogramos

C) Inscripção dos polygonos.

D) Determinação da area dos polygonos regulares.

E) Determinação da extensão da circunferência e da área do circulo.

F) Exercicios práticos sobre volume de alguns sólidos geométricos. (PARANÁ, 1921b, p. 20). 
O como ensinar foi motivo de angústia de muitos professores primários, em especial os professores não normalistas, da mesma forma o Inspetor Geral da Instrução Pública se preocupou e como ação para sanar a dificuldade dos professores paranaenses e também traçar as diretrizes desejadas pelo governo do Paraná lançou uma publicação da Inspetoria Geral do Ensino de 1921, assinada por ele mesmo, Cesar Prieto Martinez, na qual são dadas "Instrucções aos professores públicos do Estado do Paraná" (PARANÁ, 1921a).

Numa espécie de conversa com o professor, Martinez vai orientando os professores sobre os encaminhamentos metodológicos de cada matéria e a importância de cada uma no currículo do ensino primário. Assim, norteava-os Martinez:

"Ensinae pois, a ler a escrever e a contar, sem vos esquecerdes que, durante o horario escolar, para amenizar e completar o ensino, deveis leccionar a Historia, a Geographia Patria e todos os conhecimentos que visam preservar a saúde contra as doenças, ou aconselhar a cura dos males que nos affligem”. (PARANÁ, 1921a, p. 5).

De acordo com as orientações do Inspetor Cesar Martinez em 1921, Linguagem, Leitura e Aritmética eram as matérias que demandavam maior esforço e, portanto, teriam que ser lecionadas nas primeiras horas da aula, antes que as crianças estivessem cansadas demais para aprender. Segundo esse Inspetor Geral da Instrução Pública do Paraná, ler, escrever e contar eram as finalidades principais da escola primária e "para amenizar e completar o ensino" os professores do ensino primário deveriam "leccionar" as demais matérias, assim como, aconselhar e dar bons exemplos às crianças (PARANÁ, 1921a, p. 5).

Nessa época, o Método Intuitivo era prescrito como um método moderno e eficaz para o ensino e por esse método considerava a Inspetoria Geral que seria mais fácil para os professores ensinarem seus alunos. Sobre esse assunto, Cesar Martinez (PARANÁ, 1921a) afirma “[...] Ensinar a ler, escrever e contar é tão fácil, porem, pelos methodos modernos, que a ninguém mais é dado apresentar desculpas". Ele referia-se à dificuldade que os professores primários do Paraná sentiam em relação ao método para ensinar, em especial, para alfabetizar crianças do $1^{\circ}$ ano. Tal dificuldade parecia decorrente da formação dos professores, visto que muitos não tinham a formação pedagógica e mesmo os professores normalistas que possuíam uma formação geral pareciam não contemplar o Método Intuitivo em suas aulas, sendo as disciplinas da área de matemática incluídas nessa formação geral. 


\section{Considerações finais}

A formação matemática do professor primário das escolas paranaenses foi alvo de transformações, ao longo dos anos. As Escolas Normais foram alterando os seus "modos de pensar" e de "fazer" em relação ao ensino das matemáticas, embora houvesse sutis permanências.

A matemática ensinada aos normalistas nos primeiros anos de 1920 foi aos poucos cedendo lugar para uma nova e diferente matemática: na denominação, nos programas, nos métodos e, sobretudo, na concepção do seu ensino, que com sucessivas adaptações foi se adequando às finalidades das Escolas Normais, que chegou a meados dos anos de 1930 propondo um ensino de matemática que primava mais pela qualidade.

Sendo assim, este estudo destacou momentos e fatos que levaram a Escola Normal a propiciar uma formação mais próxima e articulada às finalidades da escola primária. Reorganizadas, as disciplinas escolares vão se distanciando da cultura da escola secundária, intervindo na formação matemática dos normalistas segundo expectativas do que a sociedade esperava do professor primário no que se refere ao ensino da matemática escolar: ensinar de modo intuitivo e prático saberes elementares matemáticos para a vida cotidiana.

O estudo mostra que o avanço dado à formação para o exercício do magistério e ensino dos saberes elementares nas escolas primárias do estado teve notória participação de Prieto Martinez, que como Diretor da Instrução Pública do Paraná, buscou atenuar problemas da formação do professor primário, inserindo novos métodos e modernas recomendações pedagógicas na formação, com vistas à melhoria das práticas docentes nas escolas primárias do estado, uma estratégia audaciosa do projeto educativo empreendido por ele no estado, em tempos da Reforma da Escola Normal proposta por Lisymaco Ferreira da Costa, nos anos de 1920.

Consideramos ainda que o presente estudo não teve como objetivo analisar como as mudanças ocorridas no curso de formação das Escolas Normais paranaenses foram apropriadas pelos futuros professores primários, mas tão somente analisar os documentos que trazem registros das mudanças ocorridas nesses cursos. Silva e Valente (2013, p. 71), ao pesquisarem sobre o ensino de Geometria em tempos de impérios, defendem que a "[...] a legislação escolar constitui um corpus documental mais acessível para uma investigação inicial”. Desse modo, foi possível neste estudo compreender a partir dos documentos oficiais as propostas para o ensino das disciplinas matemáticas e suas metodologias 
nas Escolas Normais paranaenses e a importância das modificações propostas e efetivadas para a formação dos professores primários da década de 1920.

Em 1937, Manoel Ribas (1937, p. 36), Interventor do Estado do Paraná, afirma:

[...] já estarem solucionados os problemas inadiáveis como a experimentação de programas mínimos elaborados segundo as lições da psicologia diferencial e experimental, dos níveis de aproveitamento e escolaridade e da melhor adaptação do conhecimento às tendências de ensino criados pelos mais altos expoentes da ciência educacional da atualidade.

$\mathrm{O}$ destaque dado pelo Interventor do estado à reforma dos métodos e processos de ensino permite-nos afirmar a importância das mudanças ocorridas na década de 1920 para os avanços da educação paranaense.

Apesar de muitos dos conteúdos matemáticos do Programa dos Grupos Escolares do Estado do Paraná, sob a Portaria n 86 e de acordo com a Lei n ${ }^{\circ}$ 1.999, de 9 de abril de 1920 (STRAUBE, 1993), estarem presentes em livros do século XIX e mesmo em propostas para a Escola Normal de outros estados, como São Paulo, entendemos a relevância deste estudo, não no sentido de apontar originalidades na Escola Normal paranaense, mas assinalar para a importância das modificações propostas pelo reformadores do Paraná, em especial, as propostas de Lysímaco Ferreira da Costa e Cesar Prieto Martinez, quanto à introdução das Metodologias de Aritmética e Geometria, que foram inovadores e um passo inicial no sentido de buscar articular os saberes matemáticos aprendidos pelos normalistas com os saberes matemáticos a serem ensinados por estes nas escolas primárias do Paraná, buscando criar "nexos comuns" entre a formação matemática da Escola Normal e a prática dos professores normalistas nas escolas primárias (CHERVEL,1990).

\section{Notas}

${ }^{1}$ Destacamos, entre outros, os estudos de França (2015), Felisberto (2014), Pinto (2015) e Portela (2014). Tais estudos integram um projeto local, denominado "A circulação e apropriação de saberes elementares matemáticos do ensino primário no estado do Paraná (1903-1970)" e financiado pelo CNPq, em curso no Grupo de Pesquisa História das Disciplinas Escolares (GPHDE) que aglutina pesquisadores e alunos em busca de compreensão da constituição dos saberes elementares matemáticos que circularam e foram apropriados no ensino primário do estado.

${ }_{2}$ São os "[...] saberes que devem ser ensinados primeiramente na escola, na escola elementar" (VALENTE, 2015, p. 204).

${ }^{3}$ A Escola Normal do Paraná iniciou em 1876 com esta denominação. Com a implantação das Bases Educativas para a Nova Escola Normal Secundária e a criação das Escolas Normais de Ponta Grossa e Paranaguá, passou a denominar-se Escola Normal Secundária (também formava professores para lecionar nas Escolas Normais), enquanto as outras duas eram Escolas Normais Primárias. 
${ }^{4}$ No Repositório da UFSC podem ser localizados documentos como fontes históricas de diferentes estados brasileiros fundamentais para as pesquisas historiográficas regionais para a História da Educação Matemática. Disponível em: <https://repositorio.ufsc.br/handle/123456789/98958>. Acesso em: 26 abr. 2016.

${ }^{5}$ Reformas que, impelidas pelos ideais de renovação, ocorreram em diversos estados brasileiros sob o comando de líderes intelectuais desses estados e cujo processo, segundo Saviani (2011, p. 177), alterou a instrução pública "em variados aspectos como a ampliação da rede de escolas; o aparelhamento técnicoadministrativo; a melhoria das condições de funcionamento; a reformulação curricular; o início da profissionalização do magistério; a reorientação das práticas de ensino; e, mais para o final da década, a penetração do ideário escolanovista".

${ }^{6}$ De acordo com Saviani (2011, p. 175) "A Reforma Sampaio Dória abriu o ciclo de reformas estaduais" da década de 1920. Sampaio Dória foi o intelectual condutor da Reforma desse período.

${ }^{7}$ Esse ideal de modernidade perpassava o ideário de um "[...] projeto de nacionalidade e de racionalidade capitalista, cujo instrumento seria a educação" (COSTA; SCHENA; SCHMIDT, 1997, p. 81), e foi na década de 1920 "[...] que a versão tradicional da pedagogia liberal foi suplantada pela versão moderna" (SAVIANI, 2011, p. 177). Embora possamos ter diversos significados para o termo "modernidade" como apontam Carvalho (1999). Nagle (1977), entre outros, o referido termo explicita aqui uma postura e que passava por uma educação que tivesse novos métodos que romperiam com a educação mais tradicional e que não mais cumpria o seu papel social.

${ }^{8}$ O Instituto de Preparatórios era responsável pela preparação em nível secundário dos jovens que pretendiam ingressar nos Cursos Superiores do Paraná (STRAUBE, 1993).

9 Entre as disciplinas do Curso Geral encontravam-se Português, Aritmética, Geometria, Geografia, História, Desenho, Química, Física, Música, Ginástica e Trabalhos Manuais.

${ }^{10}$ As disciplinas do Curso Especial eram específicas para preparar o normalista para exercer a função de professor, como Pedagogia, Psicologia e as Metodologias.

${ }^{11}$ Essa complementação de um ano com as matérias pedagógicas era possível e legal porque os programas das Escolas Normais Primárias, do Curso Geral e dos ginásios (todos cursos secundários) eram os mesmos.

${ }^{12}$ Lente era a denominação dos professores com formação no Curso Normal Secundário ou nos Cursos Superiores concursados para lecionar nas Escolas Normais do estado.

${ }^{13}$ Tais Reformas ocorreram em esfera nacional, como a Lei Francisco Campos, em esfera estadual, como as Reformas dos diversos estados brasileiros nas décadas de 1920 e 1930, e em esfera municipal, a partir da década de 1990 e não se articula com o nosso objeto de estudo.

${ }^{14}$ Entre os professores engenheiros (ou engenheiros professores) podemos citar: Oswaldo Pilotto, Engenheiro Agrônomo e Civil, foi professor de Matemática na Escola Normal Secundária, em Curitiba; Algacyr Munhoz Maeder, professor de matemática do Ginásio Paranaense. E entre os professores médicos estava Antonio de Siqueira Gusso, professor de Matemática na Escola Normal Primária de Paranaguá.

${ }^{15}$ A diferença na nomenclatura para Mathematicas nas aulas de Martinez possivelmente se deve ao movimento que visava acabar com a divisão da Matemática escolar em partes distintas e separadas (Aritmética, Álgebra e Geometria) e que tinha como o seu principal defensor no Brasil o ilustre professor e mais tarde diretor do Colégio Dom Pedro II, Euclides Roxo.

${ }^{16}$ Não tivemos acesso a documentos que elucidassem sobre o que seria o histórico da disciplina Aritmética, mas a nossa hipótese é de que seja a história da disciplina e a justificativa para sua presença nos programas, como se faz nos dias atuais, por exemplo, no Planejamento Pedagógico Curricular do Paraná, em cada disciplina do currículo.

${ }^{17}$ Importante lembrar que a Escola de Aplicação foi criada com a finalidade de aprendizagem das técnicas de ensino pela prática dos normalistas, que precisavam de uma escola para "aplicar" os conhecimentos adquiridos na Escola Normal. 


\section{REFERÊNCIAS}

BRASIL. Decreto $\mathrm{n}^{\circ}$. 11.530, de 18 de março de 1915. Disponível em:

<http://www2.camara.gov.br/legin/fed/decret/1910-1919/decreto-11530-18-marco-1915-522019republicacao-97760-pe.html> Acesso em 21/09/2012.

CAMARA, Alexsandra; PINTO, Neuza Bertoni. A Geometria no Ensino Primário da Década de 19201930. In: ENCONTRO NACIONAL DE PESQUISA EM HISTÓRIA DA EDUCAÇÃO MATEMÁTICA, 2., 2014, Bauru. Anais... Bauru, SP: UNESP, 2014. Disponível em: $<$ http://www2.fc.unesp.br/enaphem/>. Acesso em: 15 maio 2015.

CARVALHO, Marta Maria Chagas de. O território do consenso e a demarcação do perigo: política e memória do debate educacional dos anos 1930. In: FREITAS, Marcos Cézar de (Org.). Memória intelectual da educação brasileira. Bragança Paulista, SP: EDUSF, 1999. p. 17-30.

CHARTIER, Roger. A História Cultural: entre práticas e representações. Lisboa: DIFEL, 1990.

CHARTIER, Roger. A ordem dos livros. Leitores, autores e bibliotecas na Europa entre os séculos XIV e XVIII. Trad. Mary Del Priore. Brasília: Editora da UnB, 1994.

CHERVEL, André. História das disciplinas escolares: reflexões sobre um campo de pesquisa. Teoria \& Educação, Porto Alegre, RS, n. 2, p. 177-229, 1990.

COSTA, Lysimaco Ferreira da. Bases Educativas para a Organização da Nova Escola Normal Secundária do Paraná. Curytiba, PR: Escola Normal Segundaria, 1923. Disponível em: <https://repositorio.ufsc.br/xmlui/handle/123456789/123699>. Acesso em: 30 abr. 2015.

COSTA, Maria José. Franco Ferreira da. Lysímaco Ferreira da Costa: a dimensão de um homem. Curitiba, PR: Imprensa da UFPR, 1987.

COSTA, Maria José Franco Ferreira da; SCHENA, Denilson Roberto; SCHIMIDT, Maria Auxiliadora. I Conferência Nacional de Educação. Brasília: INEP/MEC, 1997.

FELISBERTO, Lidiane Gomes dos Santos. A concepção de Concreto na Aritmética da Escola Primária do Paraná (1901-1932). 2014. Dissertação (Mestrado em Educação) - Pontifícia Universidade Católica do Paraná, Curitiba, 2014.

FRANÇA, Iara da Silva. Do Ginásio para as Escolas Normais: as mudanças na formação matemática dos professores do Paraná (1920-1936). 2015. Tese (Doutorado em Educação) - Pontifícia Universidade Católica do Paraná, Curitiba. 2015.

MARTINEZ, Cesar Prieto. Relatório do Inspetor Geral da Instrução Pública. Coritiba: Typ. Penitenciaria do Estado do Paraná, 1920. Disponível em: <https://repositorio.ufsc.br/handle/123456789/99764>. Acesso em: 30 abr. 2015. 
MARTINEZ, Cesar Prieto. Relatório do Inspetor Geral da Instrução Pública. Curitiba: Typ. da Penitenciária do Estado, 1922. Disponível em:

<https://repositorio.ufsc.br/xmlui/handle/123456789/99956>. Acesso em: 30 abr. 2015.

MARTINEZ, Cesar Prieto. Relatório do Inspetor Geral da Instrução Pública. Curitiba: Typ. da Penitenciária do Estado, 1924. Um exemplar encontra-se disponível no Instituto Histórico e Geográfico de Paranaguá.

MONARCHA, Carlos. Brasil Arcaico, Escola Nova: ciência, técnica \& utopia nos anos 1920-1930.

São Paulo: Editora da UNESP, 2009.

NAGLE, Jorge. A educação na Primeira República. In: FAUSTO, Boris (Org.). História Geral da Civilização Brasileira. São Paulo: Difel, 1977. Tomo 3. v. 2. p. 261-291.

PARANÁ. Decreto n. 710, de 18 de outubro de 1915. Código do Ensino do Estado do Paraná. Diario Official, Coritiba, PR, 2 dez. 1915. Disponível em:

<https://repositorio.ufsc.br/xmlui/handle/123456789/99744>. Acesso em: 30 abr. 2015.

PARANÁ. Decreto n. 17, de 9 de janeiro de 1917. Código do Ensino do Estado do Paraná. Diario Official, Coritiba. 1917. Disponível em: <https://repositorio.ufsc.br/handle/123456789/125257>. Acesso em: 30 abr. 2015.

PARANÁ. Inspetoria Geral do Ensino. Instrução aos Professores Publicos do Estado do Paraná. Curitiba: Livraria Econômica, 1921a. Disponível em:

<https://repositorio.ufsc.br/handle/123456789/105309>. Acesso em: 30 abr. 2015.

PARANÁ. Inspetoria Geral do Ensino. Programa dos Grupos Escolares do Estado do Paraná. Curitiba: Irmãos Guimarães e Cia., 1921b. Disponível em: <https://repositorio.ufsc.br/handle/123456789/105310>. Acesso em: 30 abr. 2015.

PARANÁ. Relatório de Lysímaco Ferreira da Costa apresentado ao Exmo. Sr. Secretário D’Estado Alcides Munhoz. In: PARANÁ. Relatório Secretaria Geral do Estado do Paraná. Curytiba, PR: Typ. A Republica. Curityba, 1924.

PINTO, Neuza Bertoni. A disciplina Complementos de Matemática na formação dos pedagogos em meados do século XX. In: ENCONTRO NACIONAL DE EDUCAÇÃO MATEMÁTICA, 11., 2013, Curitiba. Anais... Curitiba: PUC/PR. 2013. 1 CDROM.

PINTO, Neuza Bertoni. Aritmética prática na Revista “A Escola” (1906-1910). In: SEMINÁRIO TEMÁTICO “SABERES ELEMENTARES MATEMÁTICOS DO ENSINO PRIMÁRIO (18901970): O QUE DIZEM AS REVISTAS PEDAGÓGICAS (1890-1970)?”, 12.. 2015, Curitiba. Anais.... Curitiba: PUC/PR, 2015.

PORTELA, Mariliza Simonete. As Cartas de Parker na Matemática da Escola Primária paranaense na primeira metade do século XX: circulação e apropriação de um dispositivo didático. 2014. Tese (Doutorado em Educação) - Pontifícia Universidade Católica do Paraná, Curitiba, 2014. 
RIBAS, Manoel. Mensagem de Manoel Ribas à Câmara dos Deputados. Curtiba, 1937.

SAVIANI, Dermeval. Pedagogia histórico-crítica: primeiras aproximações. 11. ed. Campinas, SP: Autores Associados, 2011.

SILVA, Maria Célia Leme da; VALENTE, Wagner Rodrigues. Programas de geometria no ensino primário paulista: do império à primeira república. Horizontes, Itatiba, SP, v. 31, p. 71-79, 2013.

STRAUBE, Ernani C. Do Liceo de Coritiba ao Colégio Estadual do Paraná, 1896-1943. Curitiba, PR: Fundepar, 1993.

TANURI, Leonor Maria. O Ensino Normal no Estado de São Paulo, 1890-1930. Estudos e Documentos, São Paulo, v. 16, p. 111-30, 1979.

VALDEMARIN, Vera Teresa. O método intuitivo: os sentidos como janelas e portas que se abrem para um mundo interpretado. In: SOUZA, Rosa Fátima de; VALDEMARIN, Vera Teresa; ALMEIDA, Jane Soares de. O legado educacional do século 19. Araraquara, SP: UNESP, 1998. p. 63-105.

VALENTE, Wagner Rodrigues. A constituição do elementar matemático: uma análise de programas de ensino (São Paulo, 1890-1950). Educação Unisinos, São Leopoldo, RS, v. 19, n. 2, maio/ago. 2015. 
Mathematics training for the teaching of basic knowledge in times of teaching school reform of Parana (Year 1920)

\begin{abstract}
The article discusses the mathematical training of primary teachers in Paraná and aims to understand how elementary mathematical knowledge was included in the reform carried out by Lysimaco Ferreira da Costa, in the 1920's and directed by Prieto Martinez for the modernization of the state's primary education. Supported by theoretical and methodological framework of cultural history, this study is guided by the question: Considering the Reform of teaching school and thinking about the mathematics education of Paraná teachers, what has changed, why has it changed and what for? With the reform subjects more focused on practical teaching in primary school were introduced, and that favored the renewal of teaching methods and teaching resources, curriculum reorganization which reflected in the quality of Math education of future teachers in the state's primary education.
\end{abstract}

Keywords: Mathematics Teaching. Primary Education Teacher. History of Education.

Iara da Silva França

E-mail: isfranca@gmail.com

Neuza Bertoni Pinto

E-mail: neuzabertonip@gmail.com

\begin{abstract}
Mathématiques formation pour l'enseignement des connaissances de base dans les temps de la Réforme de l'école normale de Parana (Année 1920)
\end{abstract}

\section{Résumé}

L'article traite de la formation mathématique des enseignants du primaire à Paraná et vise à comprendre comment les connaissances de base mathématique ont été inclus dans la réforme adoptée par Lysimaco Ferreira da Costa effet en 1920 et dirigé par Prieto Martinez pour la modernisation de l'enseignement état primaire. Pris en charge par le cadre théorique et méthodologique de l'histoire culturelle, cette étude est guidé par la question: dans l'enseignement des mathématiques des enseignants Paraná, ce qui a changé, pourquoi et ce qui a changé après la réforme de l'école normale? Avec la réforme ont été introduits des disciplines plus axées sur de pratiques à l'école primaire et qui ont favorisé le renouvellement des méthodes d'enseignement et ressources pédagogiques, réorganisation curriculaire qui reflète dans la qualité de formation mathématique des futurs instituters et dans la modernisation pédagogique de l'école primaire dans l'État.

Mots-clé: Formation des enseignants. Professeur de l'enseignement primaire. Histoire de l'éducation.

Enviado em: 25/5/2015

Aprovado em: 17/12/2015 